\title{
Acute kidney injury following acute pancreatitis: A review
}

\author{
Nadezda Petejova, Arnost Martinek
}

Backround. Acute kidney injury (AKI) is a common serious complication of severe acute pancreatitis (SAP) and an important marker of morbidity and mortality in critically ill septic patients. AKI due to severe acute pancreatitis can be the result of hypoxemia, release of pancreatic amylase from the injured pancreas with impairment of renal microcirculation, decrease in renal perfusion pressure due to abdominal compartment syndrome, intraabdominal hypertension or hypovolemia. Endotoxins and reactive oxygen species (ROS) also play an important role in the pathophysiology of SAP and AKI. Knowledge of the pathophysiology and diagnosis of AKI following SAP might improve the therapeutic outcome of critically ill patients.

Methods and Results. An overview of the pathophysiology, diagnosis and potential treatment options based on a literature search of clinical human and experimental studies from 1987 to 2013.

Conclusions. Early recognition of AKI and SAP in order to prevent severe complication like septic shock, intraabdominal hypertension or abdominal compartment syndrome leading to multiple organ dysfunction syndrome is a crucial tool of therapeutic measures in intensive care.

Key words: acute kidney injury, biomarkers, blood purification, intraabdominal hypertension, renal replacement therapy, multiple organ dysfunction syndrome, pathophysiology, severe acute pancreatitis, treatment options

Received: April 25, 2013; Accepted: June 7, 2013; Available online: June, 17, 2013

http://dx.doi.org/10.5507/bp.2013.048

Department of Internal Medicine, University Hospital Ostrava and Faculty of Medicine, University of Ostrava, Czech Republic Corresponding author: Nadezda Petejova, e-mail: petejova@seznam.cz

\section{INTRODUCTION}

Severe acute pancreatitis (SAP), as one of the presentations of clinically acute abdomen is a systemic disease in which the local inflammatory pathological changes of the pancreas involve multiple organs ${ }^{1}$. SAP is an acute clinical syndrome characterised by acute onset, rapid progression, high incidence of complications and high mortality, estimated as from $7 \%$ to $47 \%$ (ref. ${ }^{2,3}$ ). One common complication of SAP in critically ill patients due to intraabdominal hypertension, septic shock and/or abdominal compartment syndrome is acute kidney injury (AKI). The presence of AKI means higher risk of morbidity and mortality and also leads to increase in the economic cost of treatment. AKI in the setting of SAP has been shown to have a 10 -fold increase in mortality ( $74.7 \%$ versus $7 \%$ ) in a study of 563 patients $^{3}$. Another study reported an overall mortality rate of $81 \%$ and $75 \%$, respectively, in patients with acute pancreatitis from AKI (ref., ${ }^{4,5}$ ). This syndrome is characterised by rapid loss of kidney excretory function and is typically diagnosed by the accumulation of end products of nitrogen metabolism (urea and creatinine) or decreased urine output, or both ${ }^{6}$. The exact mechanism of AKI in patients with SAP is still unclear and it may involve many factors. The combination of renal disease and SAP can occur as a result of systemic conditions that affect many organs not only kidney and pancreas. One important question, therefore, is how to assure an early diagnosis of AKI before tubular dysfunction occurs and thus hopefully prevent progression to established AKI $\left(\right.$ ref. $^{7}$ ). The Acute Dialysis Quality Initiative (ADQI) is an ongoing project that aims to produce evidence-based recommendations for the prevention and management of AKI ( ref. $^{7-9}$ ). In intensive care we can use for diagnosis of AKI, the RIFLE (risk, injury, failure, loss, end stage) and Acute Kidney Injury Network (AKIN) criteria ${ }^{10,11}$. The key laboratory and clinically indicators are serum creatinine, urine output and glomerular filtration rate. The recent recommendation of The Kidney Disease Improving Global Outcomes (KDIGO) is to use a uniform definition of AKI, based on urinary output and on changes in serum creatinine level ${ }^{12}$. Both criteria are taken into account and AKI is divided into three stages (Table 1).

Table 1. KDIGO criteria for classification of AKI (ref. ${ }^{12,13}$ )

Stage 1

a) Scr increased $1.5-1.9$ times baseline or

b) $\mathrm{Scr}>0.3 \mathrm{mg} / \mathrm{dL}(26.5 \mu \mathrm{mol} / \mathrm{L})$ or

c) $\mathrm{UO}<0.5 \mathrm{~mL} / \mathrm{kg} / \mathrm{h}$ during a $6 \mathrm{~h}$ period Stage 2

a) Scr increase 2.0-2.9 times baseline or

b) $\mathrm{UO}<0.5 \mathrm{~mL} / \mathrm{kg} / \mathrm{h}$ during two $6 \mathrm{~h}$ periods Stage 3
a) Scr increase $>3$ times baseline or
b) $\mathrm{Scr}$ increase to $0.4 \mathrm{mg} / \mathrm{dL}(353 \mu \mathrm{mol} / \mathrm{L})$ or
c) Initiation of RRT or
d) UO $<0.3 \mathrm{~mL} / \mathrm{kg} / \mathrm{h}$ during more than $24 \mathrm{~h}$ or
e) Anuria for more than $12 \mathrm{~h}$

Scr - Serum Creatinine, UO -Urine Output, RRT - Renal Replacement Therapy 
There are also changes in the classification of SAP. The original Atlanta classification of 1992 was revised and updated by the working group and identifies two phases of acute pancreatitis: early (first one or two weeks) and late (thereafter). The severity of AP is categorized into three levels: mild, moderately severe and severe, according to the incidence of local and systemic organ complications ${ }^{14}$.

Knowledge of the pathophysiology of SAP and the following AKI might improve the therapeutic outcome of critically ill patients.

\section{PATHOPHYSIOLOGY}

Due to the difficult access to the pancreas in the sense of acute intervention or biopsy in critical conditions, the pathophysiology of SAP and AKI was studied using an animal model. Experimental models of SAP have been the most commonly performed on rats or cell cultures. In the pathophysiology of both diseases it is important that AKI can develop by the same mechanisms as SAP and is also a severe complication of acute pancreatitis. Different events are associated with AKI due to severe acute pancreatitis. These include hypoxemia, release of pancreatic amylase from the injured pancreas with resulting impairment of renal microcirculation, decrease in renal perfusion pressure due to abdominal compartment syndrome, intraabdominal hypertension and hypovolemia. Endotoxins and reactive oxygen species (ROS) also play an important role in the pathophysiology of SAP and AKI. In 1992, a study was reported on the relationship between renal tubular cell injury and serum phospholipase $\mathrm{A}_{2}\left(\mathrm{PLA}_{2}\right)$ activity in acute pancreatitis. Pancreatic phospholipase $\mathrm{A}_{2}$ was rapidly deposited in renal proximal tubular cells causing damage. However, the exact mechanism of cell toxicity was unknown ${ }^{15}$. Recent studies provide a more comprehensive view. A large amount of PLA $\mathrm{A}_{2}$ is released by polymorphonuclear leukocytes and mononuclear macrophages when SAP occurs and this causes degradation of phospholipids characterized by acute inflammation and necrosis of pancreatic parenchyma, necrosis of pancreatic fat, hemorrhage and inflammatory infiltration ${ }^{16,17}$. Pancreatic and kidney cells may die according to either necrosis or apoptosis mechanisms. In contrast to necrosis, apoptosis is an energy dependent mechanism. Apoptosis occurs in the segment of the distal nephron, which is relatively resistant to ischemic injury and necrosis occurs more in the proximal nephron. In pancreatics acinar cells, induction of oxygen free radicals promote apoptosis whereas their inhibition leads to an increase in necrosis accompanied by reduced ATP (ref. ${ }^{17}$ ). The apoptotic pathway is an active process requiring specific proteins, proteases (now called caspases). Caspase activation is a point of no return in the cell death pathway and even if caspase activity is inhibited this usually just results in diversion into a cell death pathway, independent of these proteases. When talk about cell death in relation to the kidney, we have to take into account the cell cycle events - specifically mechanisms of the $\mathrm{G}_{1}$ phase cell arrest - and this relationship was best described by Price et al (ref. ${ }^{18}$ ). Severe forms of pancreatitis exhibit disbalance in the proteaseantiprotease system with activation of the complement system, release of factor $\mathrm{C} 5 \mathrm{a}$, which in turn stimulates macrophage and neutrophil recruitment. This further promotes intraperitoneal inflammation and cytokine activation via transcription factors such as nuclear factor kappa B (NFkB). The release of activating cytokines involves both pro-inflammatory (tumor necrosis factor, interleukins IL-1, IL-6, IL-8 and platelet activating factor) and anti-inflammatory (interleukins IL-2, IL-10 and IL11) cytokines ${ }^{19}$. Systemic inflammation with increase in vascular permeability leads to exsudation with inflammatory fluid accumulation in intraabdominal and retroperitoneal cavities and increase in intraabdominal pressure with resultant intraabdominal hypertension (IAH) $\left(\right.$ ref. $\left.^{20}\right)$. Abdominal compartment syndrome (ACS) is a severe complication of SAP and is significantly associated with patient prognosis. The increased intra-abdominal pressure (IAP) reduces the blood supply to the abdominal organs, leading to low perfusion in the kidneys and this is a common cause of AKI ( ref. $^{21}$ ). Changes in visceral blood flow with elevated IAP were well-described by Caldwell's research work in 1987 (ref. ${ }^{22}$ ). Later in another study it has been reported that IAH leads to decreased renal arterial blood flow and decreased perfusion of renal cortex ${ }^{23}$. All these changes shunt blood away from the renal cortex leading to impaired glomerular and tubular function and significant reduction in urinary output ${ }^{24,25}$. However, AKI in SAP is much more complex and renal blood flow is also altered because of changes in intrarenal hemodynamics during sepsis. For this reason, of ventilation with positive end expiratory pressure which can reduce renal perfusion pressure (RPP) should also be used (ref. ${ }^{26}$ ). RPP can be defined as mean arterial pressure (MAP) minus IAP ( ref. $^{23}$ ). The earliest signs of increasing IAP include oliguria and renal dysfunction ${ }^{27}$. These changes occur in direct response to increasing IAP with oliguria developing at an IAP of $15 \mathrm{mmHg}$ and anuria at $30 \mathrm{mmHg}\left(\right.$ ref. $^{24}$ ). Another mechanism proposed to explain this kidney alteration is direct renal compression with consequent ischemia and renal failure ${ }^{28}$. Several studies have shown a relationship between intraabdominal hypertension (IAH) and AKI. IAP of $12 \mathrm{mmHg}$ was the optimal cut off for AKI defined using the RIFLE classification in the study of 123 patients treated on general ICU (ref. ${ }^{29}$ ). As the duration and intensity of IAP increases, direct compression of heart, lungs and aorta results in decreased cardiac output, potentially misleading elevations in central venous pressure and pulmonary arterial occlusion pressure, increased intrathoracic pressure and hypoxia ${ }^{27}$. However, correction of cardiac output by volume loading does not prevent AKI as has been shown in animal experiments ${ }^{30}$. Conversely, excess fluid overload in critically ill patients can lead to increased intraabdominal hypertension due to endothelial dysfunction, increase of capillary permeability and leak of fluids into the third space. Further, decreased urine output and glomerular filtration are not only altered during SAP with IAH. IAH also affects plasma renin activity (PRA) and aldosterone (ALDO) levels ${ }^{31}$. Direct renal compression and renal venous hypertension increases 
renal vascular resistance by obstructing renal venous outflow and has been associated with renal dysfunction and significant increase in PRA and ALDO levels ${ }^{31}$. Urinary sodium and chloride concentrations decreased significantly with elevated IAP and returned to normal with abdominal decompression ${ }^{32}$. Activation of proteolytic enzymes, lipase, kinins and other active peptides too may be some of the crucial mediators responsible for alterations in the renin-angiotensin-system ${ }^{33,34}$.

Understanding of the complex pathophysiology of both diseases, AKI and SAP, is required to determine adequate subsequent diagnostic and therapeutic procedure.

\section{DIAGNOSIS}

Early recognition of AKI in SAP is an important factor for potentially life-saving procedures in critically ill patients. We have no definite parameter for daily clinical routine for exact early determination of AKI diagnosis. AKI has traditionally been defined and detected by measuring serum creatinine and blood urea nitrogen concentration which can significantly increase after substantial kidney injury and with time delay ${ }^{35,36}$. The concentration of serum creatinine depends on the muscle mass and can be significantly lower in elderly and cachectic patients. Serum creatinine is also secreted by the renal tubule and this secretion can be modified by pharmacological agents $^{35}$. The glomerular filtration rate is determined from 24 hour collection of urine or using the calculation method of MDRD or Cockroft-Gault. However, both of these calculation methods are affected by errors as they are based on serum creatinine levels.

Early determination, incidence and mortality of AKI has been investigated in several clinical studies ${ }^{37-41}$. Bagshaw et al has described examination of urine microscopy and urinary biochemical tests in septic AKI. In this study, the authors focused on differential diagnostics to distinguish between pre-renal azotemia from acute tubular necrosis using urine sodium (UNa), fractional excretion of sodium ( $\mathrm{FeNa}$ ) and fractional excretion of urea (FeUrea) (ref. ${ }^{42}$ ). UNa was found to be highly variable and depended on time changes and use of diuretics. However, UNa values $>40 \mathrm{mmol} / \mathrm{L}$ were more consistent with ATN. The detection of FeNa is based on the physiological principle that filtered sodium is reabsorbed by the renal tubules in pre-renal azotemia $(\mathrm{FeNa}<1 \%)$ and not in ATN $(\mathrm{FeNa}>1 \%)$. However, in patients treated with diuretic agents or on rhabdomyolysis, contrast nephropathy and hypo- and hyperaldosteronism, the results may unclear ${ }^{42,43}$. In contrast to $\mathrm{FeNa}$, the FeUrea $\geq 35 \%$ has been shown to have greater sensitivity and specificity in determination of septic AKI (ref. ${ }^{44}$ ). Renal tubular cells and muddy brown, hyaline or granular casts have been commonly found in urine microscopy of septic ATN (ref. ${ }^{45}$ ).

On the other hand, since serum creatinine is a poor predictor of AKI and is detected in serum with a timedelay, other markers of AKI are needed. Cytokines in particular are easily measured and are potential biomarkers of AKI. Several serum and urinary biomarkers have been recently investigated in AKI and characterised as more sensitive indicators of AKI than serum creatinine or urea nitrogen ${ }^{46-51}$. An ideal renal biomarker would be easily measured, inexpensive, sensitive to detection of subclinical injury and correlate prognosis with onset and severity of injury. Last but not least, it would be sensitive to renal recovery and response to therapy and allow identification of AKI subtypes and etiologies ${ }^{52-54}$. The most promising biomarkers are urine and plasma Neutrophil Gelatinase-Assotiated Lipocalin (NGAL), urine interleukin 18 (IL-18), urine Kidney Injury Molecule 1 (KIM1), plasma cystatin C, urine pi-glutathione S-transferase (pi-GST), urine tissue inhibitor of metalloproteinases-2 (TIMP-2), urine insulin-like growth factor - binding protein (IGFBP-7) and urine liver fatty acid binding protein (L-FABP) and serum and urine interleukin 6 (IL-6) $\left(\right.$ ref. $\left.^{55}\right)$. The first mentioned biomarker associated with AKI commonly detected in plasma and urine is NGAL - a 25-kDa protein covalently bound to gelatinase from neutrophils and markedly induced in injured epithelia ${ }^{53}$. NGAL is also increased in cisplatin toxicity, radiocontrast nephropathy and hypoxia mediated nephrotoxicity. The performance of serum and urine NGAL in the setting of AKI following cardiac surgery, in sepsis or burn, has been investigated in several studies in critically ill patients ${ }^{50,55-57}$. Cystatin $\mathrm{C}$ is a cysteine protease inhibitor that is synthesized and released into the blood at a relatively constant rate by all nuclear cells. It is freely filtered by the glomerulus, completely reabsorbed by the proximal tubule, and not secreted ${ }^{53}$. The use of cystatin $\mathrm{C}$ in prediction of AKI in critically ill patients has been also investigated after cardiac surgery, after application of nephrotoxic drugs and recently during renal replacement therapy for prediction a renal recovery ${ }^{58-60}$. Cytokines are also potential biomarkers of AKI and are easily measured in ICU practice. Urine and serum IL-6 increase early in patients with AKI and reflect the failure of proximal tubule metabolism of IL-6 $\left(\right.$ ref. $\left.{ }^{61}\right)$. The serum concentration of IL-6 and inter - cellular adhesion molecule 1 (ICAM -1) are also good markers for predicting SAP ( ref. $^{62}$ ).

Two multicenter observational studies in critically ill patients at risk of AKI, were recently undertaken to validate and discover cycle cell arrest biomarkers in human AKI. The primary endpoint of validation was development of moderate to severe AKI (KDIGO stage 2 to 3 ) in critically ill patients within 12 hours of sample collection. The two top biomarkers validated were: IGFBP-7 and TIMP-2 both inducers of $\mathrm{G}_{1}$ cell cycle arrest, a key mechanism implicated in AKI (ref. ${ }^{55}$ ).

\section{TREATMENT}

Clinicians have 4 aspects to consider in the management of AKI associated with SAP: 1) treatment of underlying disease (pancreatitis), 2) intraabdominal hypertension and abdominal compartment syndrome treatment measures, 3) renal function supportive measures and 4) renal replacement therapy (RRT). 


\section{Treatment of underlying disease (SAP)}

The treatment of SAP depends on illness severity and also on the patient's clinical condition. After the diagnosis of SAP, it is necessary to predict severity of the disease using various scoring systems: APACHE II, SOFA or BISAP. In the management of SAP treatment multi-discipline measures are an important step. The basic principles of SAP treatment includes usually: a) emerging hospitalisation, b) monitoring of vital function, c) restriction of oral intake, d) adequate enteral and parenteral nutrition, e) adequate analgesic treatment, f) the emplacement of nasogastric tube, $\mathrm{g}$ ) antibiotic treatment for infectious complications, h) percutaneous drainage, endoscopic therapy or abdominal laparotomy. The basic standard for diagnosis of pancreatic necrosis is contrast-enhanced computed - tomography. However, cross-sectional imaging in the early phase of evaluation is not associated with improved outcome, but is very important and usually used between 48-72 h after hospitalisation. Antibiotic treatment in SAP is still a controversial option and some studies recommend use of antibiotics agents only if the complications of sepsis are presented but not for their prevention $^{63-65}$. In addition, broad spectrum antibiotics with good tissue penetration are necessary to prevent infection in SAP after CT-proven pancreatic necrosis ${ }^{66}$. Patients suffering from infected necrosis, massive hemorrhage, bowel perforation, sterile necrosis with clinical deterioration or symptomatic organized necrosis are usually indicated for surgical intervention ${ }^{67}$.

Experimental animal studies, have reported the protective effects of dexamethasone on multiple organ injury in rats with SAP. There was no significant difference in survival between the dexamethasone treatment group and the control group of rats. Nevertheless, the pancreas, liver, lung and kidney pathological scores were significantly lower in the dexamethasone treatment group $(P<0.001$ to $P=0.046$ respectively) $\left(\right.$ ref $\left.^{68}{ }^{6}\right)$. In another study, the same authors showed the effect of dexamethasone on NF-kB expression in multiple organs in rats with SAP. They concluded that dexamethasone can lower the plasma amylase, plasma endotoxin, serum TNF- $\alpha$ and reduce the NF-kB expression in the liver and kidney and apoptosis may be a protective response to pancreatic cell injury ${ }^{1}$. Esrefoglu M. summarized experimental and clinical evidence of antioxidant therapy e.g ascorbic acid, alpha tocopherol, beta-carotene, melatonin, carnitine and $\mathrm{N}$-acetyl-cysteine in cases of AP. Use of antioxidant regimens in the management of AP as a supplement and combined with conventional therapy are reasonable, but there are no sufficient data for using them alone ${ }^{17}$. Another study on rats showed an anti-inflammatory effect of pentoxifylline by inhibiting NF-kB activation in acute pancreatitis and pancreatic ischaemia-reperfusion (I-R) models. The aim of this experimental study was to evaluate the effect of pentoxifylline administration in a rat model of pancreatic I-R injury. Significant reductions in serum TNF- $\alpha$, IL-6 and IL-10 were observed in the group treated with pentoxiphylline compared with the group without pentoxifylline $(P<0.05)$. The histologic score was significantly lower in pentoxifylline-treated animals, denoting less severe pan- creatic histologic damage. Pentoxifylline administration in this study reduced the systemic inflammatory response, the pancreatic histological lesion and renal dysfunction in pancreatic I-R injury ${ }^{69}$.

The efficacy of blood purification methods including hemofiltration or hemodialysis in the treatment of underlying SAP by ameliorating the systemic inflammatory response has been investigated in several studies.

In the early phase of severe acute pancreatitis (SAP), serious pulmonary complications which are directly correlated with mortality are very common. Endothelial injury has been shown to play a key role in the pathogenesis of acute respiratory distress syndrome (ARDS) $\left(\right.$ ref. $\left.^{70}\right)$. Continuous blood purification (CBP) has been widely used in treating patients with multiple organ dysfunction syndrome (MODS) including ARDS (ref. ${ }^{71}$ ). However, there are a recent data of a Chinese study, which investigated the efficacy of continuous venovenous hemofiltration $(\mathrm{CVVH})$ in treating SAP in previous performed studies. Four comparative studies and seven case series comprising a total of 354 patients were included. The overall mortality rate of patients receiving CVVH was $20 \%$ (55/275). After CVVH, the patient conditions improved between the $6^{\text {th }}$ and $72^{\text {nd }}$ hour. Overall however, no solid clinical evidence has proven the efficacy of CVVH in treating SAP. High-volume CVVH that is initiated early and sustained for at least $72 \mathrm{~h}$ may be adopted to investigate the efficacy of CVVH for treating SAP (ref. $\left.{ }^{71}\right)$. The aim of the Gong et al study was to investigate the effect of high-volume hemofiltration (HVHF) on ameliorating immune dysfunction in patients with severe acute pancreatitis (SAP). The patients were assigned to the standard medical treatment group (SMT group, $n=4$ ) or the HVHF group $(\mathrm{n}=8)$ at the outset, in a 1:2 ratio. The SMT group were given standard treatment for SAP, while the HVHF group were given standard as well as 72-h HVHF treatment initiated within $2 \mathrm{~h}$ of the start of the study. Plasma levels of IFN-gamma, TNF-alpha, IL-1, IL-2, IL-5, and IL13 in the HVHF group were significantly lower than those in the SMT group. Peripheral CD4+ and CD8+ T cells, monocyte count, and HLA-DR expression were increased significantly $(P<0.05)$ only in the HVHF group, not in the SMT group. In this study HVHF significantly reduced plasma inflammatory cytokine concentrations including those of IFN-gamma, TNF-alpha, IL-1, IL-2, IL-5, and IL-13, while it increased monocyte HLA-DR expression in patients with SAP $\left(\right.$ ref. $\left.^{72}\right)$. The use of different types of blood purification in non-renal indications for treatment SAP in previous human studies is summarized in Table 2.

\section{Intraabdominal hypertension and abdominal compart- ment syndrome treatment measures}

The first recommended approach is early recognition of IAP and ACS, and if the clinician needs to make that diagnosis he or she needs to measure the IAP in clinical practice. Routine measurement of IAP in patients admitted to the ICU because of SAP is rarely performed, which makes it difficult to determine the exact magnitude of the problem ${ }^{83}$. The IAP can be measured directly by an intraperitoneal catheter or indirectly by gastric or the uri- 
Table 2. Blood purification modalities on treatment SAP in human studies.

\begin{tabular}{|c|c|c|c|c|c|c|c|c|c|}
\hline Study & 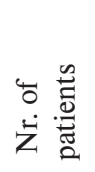 & 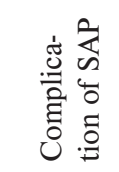 & 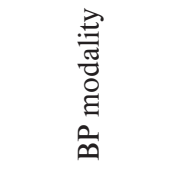 & 읍 & 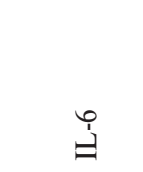 & $\stackrel{\infty}{\dot{1}}$ & $\begin{array}{l}\frac{\pi}{\pi} \\
\frac{2}{\pi} \\
\frac{L}{Z} \\
\frac{L}{V}\end{array}$ & 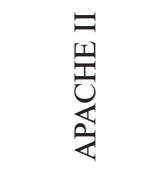 & $\begin{array}{l}\stackrel{0}{\Xi} \\
\text { ठ } \\
\stackrel{0}{0}\end{array}$ \\
\hline Chu LP et al. 2013 (ref. $\left.{ }^{73}\right)$ & 30 & MODS & $\begin{array}{l}\text { PHVHF/ } \\
\text { CVVH }\end{array}$ & decrease & $\begin{array}{l}\text { PHVHF } \\
\text { decrease> }\end{array}$ & NA & decrease & $\begin{array}{l}\text { PHVHF } \\
\text { improved }\end{array}$ & $\begin{array}{l}\text { PHVHF } \\
\text { improved }\end{array}$ \\
\hline Zhu Y et al. 2011 (ref. ${ }^{74}$ ) & 75 & MODS & HVHF & NA & NA & NA & NA & improved & improved \\
\hline Yang C et al. $2010\left(\right.$ ref. $\left.^{75}\right)$ & 51 & SIRS & $\mathrm{HF}+\mathrm{PD}$ & NA & decrease & decrease & decrease & NA & NA \\
\hline Yu C et al. $2008\left(\right.$ ref. $\left.^{76}\right)$ & 16 & SIRS & HV-CVVH & decrease & decrease & NA & decrease & improved & improved \\
\hline Pupelis et al. 2007 (ref. ${ }^{77}$ ) & 111 & $\begin{array}{l}\text { SIRS/ } \\
\text { MODS }\end{array}$ & $\mathrm{CVVH}$ & NA & NA & NA & NA & improved & improved \\
\hline Chen ZH et al. $2007\left(\right.$ ref. $^{78}$ ) & 20 & $\begin{array}{l}\text { SIRS/ } \\
\text { MODS }\end{array}$ & $\mathrm{CVVH}$ & NA & NA & NA & NA & improved & improved \\
\hline Jiang HL et al. 2005 (ref. $^{79}$ ) & 37 & SIRS & $\begin{array}{l}\text { CVVH (high/ } \\
\text { low volume) }\end{array}$ & NA & decrease & NA & decrease & NA & improved \\
\hline Oda S et al. 2005 ( ref. $^{80}$ ) & 17 & SIRS & CHDF & NA & decrease & NA & NA & NA & improved \\
\hline Wang H et al. 2003 (ref. ${ }^{81}$ ) & 28 & MODS & CHVHF & NA & NA & NA & NA & improved & improved \\
\hline Xie H et al. 2003 (ref. ${ }^{82}$ ) & 13 & MODS & $\mathrm{CVVH}$ & NA & NA & NA & decrease & improved & improved \\
\hline
\end{tabular}

BP - Blood Purification, MODS - Multiple Organ Dysfunction Syndrome, IL-6 - interleukin 6, IL-8 - interleukin 8, IL-10 - interleukin 10, SIRS Systemic Inflammatory Response Syndrome, TNF alpha - tumour necrosis factor alpha, APACHE II - Acute Physiology and Chronic Health Evaluation II score, CVVH - Continuous Venovenous Hemofiltration, NA - not available, HV-CVVH - High-Volume Continuous Venovenous Hemofiltration, PD - Peritoneal Dialysis, PHVHF - Pulse High-Volume Hemofiltration, CHDF - Continuous Hemodiafiltration, HVHF - HighVolume Hemofiltration, CHVHF - Continuous High-Volume Hemofiltration

nary bladder pressure ${ }^{84,85}$. Usually the bladder has been used as the method of choice for measuring IAP and this easy technique is a closed sterile system which does not increase the previous reported risk for urinary tract infection $^{86,87}$. One important disadvantage in the intermittent technique that interferes with urine output without the option of obtaining a continuous trend ${ }^{86}$. Comparison of intermittent and continuous intra-abdominal pressure monitoring using an in vitro-modes has been described by McBeth et al which showed no evidence to suggest the superiority of one method over the other ${ }^{88}$. The presence of IAP > $15 \mathrm{mmHg}$ was connected to higher mortality and severity of SAP and also with impaired renal function ${ }^{89}$. The management of necrotising pancreatitis has been changing over the last decade. Surgical debridement was the preferred treatment to control necrotising pancreatitis in the past. Using ultrasound or CT confirmation of ascites and pancreatic pseudocysts, the first step of IAP treatment might be percutaneous drainage. Decompressive laparotomy in high IAP 21-49 mmHg with development to ACS has been reported in several studies as the most effective way of decreasing IAP (ref. ${ }^{83,89}$ ). Plaudis et al described abdominal negative-pressure therapy in their prospective study with 25 surgical patients as a new method in countering ACS and peritonitis ${ }^{90}$. However, management of the open abdomen is still associated with a number of complications including persistent sepsis and development of multiple organ dysfunction ${ }^{91-93}$. The second step is control of fluid balance for maintenance of adequate organ perfusion and also to control the third space. Pupelis et al described the use of early continuous venovenous hemofiltration in a study with 130 critically ill patients suffering from SAP with IAH. Development of MODS and sustained increase of IAP $\geq 12 \mathrm{mmHg}$ was a strong indicator for commencement of CVVH in these patients. Application of CVVH in 75 of studied patients resulted in faster decrease in IAP during the first phase of the disease when IAP reached $10.6 \pm 3.9 \mathrm{mmHg}$ within two weeks, while the mean IAP in patients treated without CVVH was still elevated at $12.9 \pm 4.1 \mathrm{mmHg}\left(\right.$ ref. $\left.^{20}\right)$.

\section{Renal function supportive measures}

Significant risk factors for AKI in patients with SAP include history of renal disease, hypoxemia, and ACS. Measures that can prevent AKI include homeostasis maintenance, adequate perfusion of the kidneys, adequate oxygenation, and abdominal decompression to avoid ACS. As mentioned previously, adequate renal perfusion is the most desired measure for support and preservation of renal function. Further, aggressive volume resuscitation might preserve cardiac output, but is an independent predictor of developing secondary ACS (ref. ${ }^{94}$ ). In patients with IAH and septic shock, use of norepinephrine (NE) probably has an appropriate effect on maintaining renal perfusion. NE has been reported to increase renal blood flow, urine output and creatinine clearance in experimental and human sepsis through a combined increase of renal perfusion pressure and an increase in renal vascular conductance ${ }^{95-98}$. Norepinehrine is more potent than dopamine at doses ranging from $0.01-3.3 \mu \mathrm{g} / \mathrm{kg} / \mathrm{min}$ to achieve increase of MAP in hypotensive patients after fluid resuscitation ${ }^{98,99}$. The targeted mean MAP with NE therapy varied in several studies, but was as high as 75 $\mathrm{mmHg}$. Improvements in renal function with increased 
perfusion pressure, have not been demonstrated in prospective randomized studies ${ }^{100}$. Several human cell studies have shown that low-dose furosemide can improve renal hemodynamics and attenuate ischemia-induced apoptosis and high concentration of furosemide have immunosuppressive properties by reducing IL- 6 , IL- 8 and TNF- $\alpha$ (ref. ${ }^{101}$ ). On the other hand, furosemide may aid in the management of fluid overload by increasing natriuresis and diuresis ${ }^{102}$.

The option of using diuretic therapy in the case of decreasing urine output in early AKI is controversial and we need relevant randomized double-blind, placebo controlled trials of early furosemid therapy in these cases. It is important for eventually further recommendation of this treatment ${ }^{103}$.

In one experimental animal study, Zhang XP et al. reported some protective effects and the mechanism of Baicalin and Octreotide on renal injury in rats with SAP. The authors showed from histopathological tissue microarray sample of kidney inhibition of inflammatory mediators, decreasing the expression level of $\mathrm{Bcl}-2$ protein and enhancing the apoptosis-promoting effect of Bax dimmer to induce apoptosis of renal tubular cells ${ }^{104}$.

\section{Renal replacement therapy}

The renal indications for RRT or blood purification as mentioned previously in patients with AKI following SAP do not significantly differ from other critically ill patients. Fluid overload unresponsive to diuretics, severe metabolic acidosis, hyperkalaemia $(>6.5 \mathrm{mmoL} / \mathrm{L})$, severe oliguria or anuria (urine output $<200 \mathrm{~mL}$ over $12 \mathrm{~h}$ ) and clinical complications of uremia are the conventional criteria for initiation of RRT in acute kidney injury ${ }^{6}$. The choice of RRT modality intermittent or continuous is determined by the patient's clinical condition especially hemodynamic status. Continuous renal replacement therapy (CRRT) is usually preferred in patients with severe hemodynamic instability, treated with high doses of vasopressors. CRRT methods can be performed in multiple modalities: using filtration alone in continuous venovenous hemofiltration, dialysis alone in continuous venovenous hemodialysis (CVVHD) or using a combination of both physical principles in continuous venovenous hemodiafiltration (CVVHDF). The primary goal of anticoagulation for CRRT is to extend circuit life ${ }^{105}$. The patients with SAP are in high risk of bleeding and if the CRRT is given, regional citrate anticoagulation of the circuit is the best choice. Citrate can, hovewer, with inadequate use cause metabolic derangements. Full advantages of citrate can only be realized if its risk are well- controlled ${ }^{105}$. Extended daily dialysis or slow low-efficiency daily dialysis are preferred intermittent methods in hemodynamic stable patients. Clinicians have some concerns about the right timing of RRT and recovery of renal function in critically ill patients. The comparison of continuous and intermittent renal replacement therapy has been shown in a study of 191 patients with AKI including 125 patients who were treated with CVVHDF or high-flux IHD in the ICU. The primary end point of the study was all-cause mortality in the ICU and in the hospital and secondary endpoint were vasopressor requirement, hemodynamic stability and renal function recovery. Of the 64 patients who survived, 97\% had complete or partial recovery of renal function. The percentage of patients with full recovery of renal function was $50 \%$ in the CVVHDF and $42 \%$ in the IHD group. There was no difference in the number of patients or the rate of vasopressors in the two groups ${ }^{106}$. We have no relevant studies in adult patients specifically investigated for intensity of renal support in patients with AKI following SAP. For this reason, we have to determine the therapeutic approach based on results from studies on animals or experimental models. Or we can use results from human studies in all critically ill patients. Intensity of renal support in critically ill patients with AKI has been investigated in the VA/NIH study that compares intense and less intensive therapy: CVVHDF at a filtration dose $35 \mathrm{~mL} / \mathrm{kg} / \mathrm{h}$ and IHD or SLEDD 6 times per week or CVVHDF at a filtration rate $20 \mathrm{~mL} / \mathrm{kg} / \mathrm{h}$ and IHD or SLEDD 3 times per week. In this multicenter, randomized, controlled study were included 1124 adult patients. There was no added benefit from an intensive (high-dose) treatment strategy compared with more conventional, less-intensive strategy. There were no significant differences in mortality and kidney function recovery and duration of RRT (ref. ${ }^{107}$ ). The multicenter, multinational, prospective, epidemiological study - The BEST (beginning and ending supportive therapy for the kidney) with 1700 patients including 1260 who were treated with RRT, found that RRT practice was quite varied around the world. RRT practice is not aligned with the best evidence and variations in practice may be responsible for significant morbidity ${ }^{108}$.

In general, RRT treatment is usually adapted to the patient's individuality and to the clinician's experience.

\section{CONCLUSIONS}

Acute kidney injury is a known complication of severe acute pancreatitis and can lead to a poor outcome in critical illness. Early recognition of AKI and SAP to prevent severe complications like septic shock, intraabdominal hypertension and abdominal compartment syndrome leading to multiple organ dysfunction syndrome is crucial in intensive care. When renal replacement therapy is necessary, we have to consider not confusing the diseases. We can choose the best method for the patient's actual clinical condition with regard to the possibility of influencing the systemic inflammatory response, renal recovery, metabolic status and fluid management.

\section{CONFLICT OF INTEREST STATEMENT}

Author's conflict of interest disclosure: The authors stated that there are no conflicts of interest regarding the publication of this article. 


\section{REFERENCES}

1. Zhang XP, Zhang L, Chen LJ, Cheng QH, Wang JM, Cai W, Shen HP Cai J. Influence of dexamethasone on inflammatory mediators and NF-kappaB expression in multiple organs of rats with severe acute pancreatitis. World J Gastroenterol 2007;13(4):548-56.

2. Halonen KI, Leppaniemi AK, Puolakkainen PA, Lundin JE, Kemppainen EA, Hietaranta AJ, Haapiainen RK. Severe acute pancreatitis: prognostic factors in 270 consecutive patients. Pancreas 2000;21(3):266-71.

3. Kes P, Vucicević Z, Ratković-Gusić I, Fotivec A. Acute renal failure complicating severe acute pancreatitis. Ren Fail 1996;18(4):621-8.

4. Tran DD, Oe PL, de Fijter CW, van der Meulen J, Cuesta MA. Acute renal failure in patients with acute pancreatitis: prevalence, risk factors, and outcome. Nephrol Dial Transplant 1993;8(10):1079-84.

5. Takase K, Takeyama Y, Nishikawa J, Ueda T, Hori Y, Yamamoto M Kuroda Y. Apoptotic cell death of renal tubules in experimental severe acute pancreatitis. Surgery 1999;125(4):411-20.

6. Bellomo R, Kellum JA, Ronco C. Acute kidney injury. Lancet 2012;380(9843):756-66.

7. Schrier RW, Wang W, Poole B, Mitra A. Acute renal failure: definitions, diagnosis, pathogenesis, and therapy. J Clin Invest 2004;114(1):5-14.

8. Bellomo R, Ronco C, Kellum JA, Mehta RL, Palevsky P; Acute Dialysis Quality Initiative workgroup. Acute renal failure - definition, outcome measures, animal models, fluid therapy and information technology needs: the Second International Consensus Conference of the Acute Dialysis Quality Initiative (ADQI) Group.Crit Care 2004;8(4):R204-12.

9. Mehta RL, Kellum JA, Shah SV, Molitoris BA, Ronco C, Warnock DG Levin A; Acute Kidney Injury Network. Acute Kidney Injury Network: report of an initiative to improve outcomes in acute kidney injury. Crit Care 2007;11(2):R31.

10. Bagshaw SM, George C, Bellomo R; ANZICS Database Management Committe. A comparison of the RIFLE and AKIN criteria for acute kidney injury in critically ill patients. Nephrol Dial Transplant 2008;23(5):1569-74.

11. Bagshaw SM, George C, Dinu I, Bellomo R. A multi-centre evaluation of the RIFLE criteria for early acute kidney injury in critically ill patients. Nephrol Dial Transplant 2008;23(4):1203-10.

12. Kellum JA, Lameire N; for the KDIGO AKI Guideline Work Group. Diagnosis, evaluation, and management of acute kidney injury: a KDIGO summary (Part 1).Crit Care 2013;17(1):204. [Epub ahead of print]

13. Fliser D, Laville M, Covic A, Fouque D, Vanholder R, Juillard L, Van Biesen $W$-ad-hoc working group of ERBP. A European Renal Best Practice (ERBP) position statement on the Kidney Disease Improving Global Outcomes (KDIGO) clinical practice guidelines on acute kidney injury: part 1: definitions, conservative management and contrast-induced nephropathy. Nephrol Dial Transplant 2012;27(12):4263-72

14. Sarr MG. 2012 revision of the Atlanta Classification of acute pancreatitis. Pol Arch Med Wewn 2013;123(3):118-24.

15. Grönroos JM, Hietaranta AJ, Nevalainen TJ. Renal tubular cell injury and serum phospholipase A2 activity in acute pancreatitis. Br J Surg 1992;79(8):800-1.

16. Zhang $X P$, Zhang J, Ma ML, Cai $Y, X u R J$, Xie Q, Jiang $X G, Y e ~ Q$. Pathological changes at early stage of multiple organ injury in a rat model of severe acute pancreatitis. Hepatobiliary Pancreat Dis Int 2010;9(1):83-7.

17. Esrefoglu M. Experimental and clinical evidence of antioxidant therapy in acute pancreatitis. World J Gastroenterol 2012;18(39):5533-41.

18. Price PM, Safirstein RL, Megyesi J. The cell cycle and acute kidney injury. Kidney Int 2009;76(6):604-13.

19. López Martín A, Carrillo Alcaraz A. Oxidative stress and acute pancreatitis. Rev Esp Enferm Dig 2011;103(11):559-62.

20. Pupelis G, Plaudis H, Zeiza K, Drozdova N, Mukans M, Kazaka I. Early continuous veno-venous haemofiltration in the management of severe acute pancreatitis complicated with intra-abdominal hypertension: retrospective review of 10 years' experience. Ann Intensive Care 2012;2 Suppl 1:S21.

21. Li H, Qian Z, Liu Z, Liu X, Han X, Kang H. Risk factors and outcome of acute renal failure in patients with severe acute pancreatitis. J Crit Care 2010;25(2):225-9.

22. Caldwell CB, Ricotta JJ. Evaluation of intra-abdominal pressure and renal hemodynamics. Curr Surg 1986;43(6):495-8.
23. De Waele JJ, De Laet I, Kirkpatrick AW, Hoste E. Intra-abdominal Hypertension and Abdominal Compartment Syndrome. Am J Kidney Dis 2011;57(1):159-69.

24. Cheatham ML, Malbrain ML, Kirkpatrick A, Sugrue M, Parr M, De Waele J, Balogh Z, Leppäniemi A, Olvera C, Ivatury R, D'Amours $\mathrm{S}$, Wendon J, Hillman K, Wilmer A.Results from the International Conference of Experts on Intra-abdominal Hypertension and Abdominal Compartment Syndrome. II. Recommendations. Intensive Care Med 2007;33(6):951-62.

25. Cheatham ML. Abdominal compartment syndrome: pathophysiology and definitions. Scand J Trauma Resusc Emerg Med 2009;17:10.

26. Farge D, De la Coussaye JE, Beloucif S, Fratacci MD, Payen DM. Interactions between hemodynamic and hormonal modifications during PEEP-induced antidiuresis and antinatriuresis. Chest 1995;107(4):1095-100.

27. Mohmand H, Goldfarb S. Renal dysfunction associated with intra-abdominal hypertension and the abdominal compartment syndrome. J Am Soc Nephrol 2011;22(4):615-21.

28. Aspesi M, Gamberoni C, Severgnini P, Colombo G, Chiumello D, Minoja G, Tulli G, Malacrida R, Pelosi P, Chiaranda M. The abdominal compartment syndrome. Clinical relevance. Minerva Anestesiol 2002;68(4):138-46.

29. Dalfino L, Tullo L, Donadio I, Malcangi V, Brienza N. Intra-abdominal hypertension and acute renal failure in critically ill patients. Intensive Care Med 2008;34(4):707-13.

30. Schachtrupp A, Lawong G, Afify M, Graf J, Toens C, Schumpelick V. Fluid resuscitation preserves cardiac output but cannot prevent organ damage in a porcine model during $24 \mathrm{~h}$ of intraabdominal hypertension. Shock 2005;24(2):153-8.

31. Bloomfield GL, Blocher CR, Fakhry IF, Sica DA, Sugerman HJ. Elevated intra-abdominal pressure increases plasma renin activity and aldosterone levels. J Trauma 1997;42(6):997-1004.

32. Shenasky JH 2 nd. The renal hemodynamic and functional effects of external counterpressure. Surg Gynecol Obstet 1972;134(2):253-8.

33. Agarwal N, Pitchumoni CS. Acute pancreatitis: a multisystem disease. Gastroenterologist 1993;1(2):115-28.

34. Lembeck F, Griesbacher T. Pathophysiological and possible physiological roles of kinins in the pancreas. Immunopharmacology 1996;33(1-3):336-8.

35. Bonventre JV. Diagnosis of acute kidney injury: from classic parameters to new biomarkers. Contrib Nephrol 2007;156:213-9.

36. Bellomo R, Kellum JA, Ronco C. Defining acute renal failure: physiological principles. Intensive Care Med 2004;30(1):33-7.

37. Xue JL, Daniels F, Star RA, Kimmel PL, Eggers PW, Molitoris BA Himmelfarb J, Collins AJ. Incidence and mortality of acute renal failure in Medicare beneficiaries, 1992 to 2001. J Am Soc Nephrol 2006;17(4):1135-42

38. Hoste EA, Lameire NH, Vanholder RC, Benoit DD, Decruyenaere JM, Colardyn FA. Acute renal failure in patients with sepsis in a surgical ICU: predictive factors, incidence, comorbidity, and outcome. J Am Soc Nephrol 2003;14(4):1022-30.

39. Uchino S, Kellum JA, Bellomo R, Doig GS, Morimatsu H, Morgera S, Schetz M, Tan I, Bouman C, Macedo E, Gibney N, Tolwani A, Ronco C; Beginning and Ending Supportive Therapy for the Kidney (BEST Kidney) Investigators. Acute renal failure in critically ill patients: a multinational, multicenter study. JAMA 2005 17;294(7):813-8.

40. Himmelfarb J, Joannidis M, Molitoris B, Schietz M, Okusa MD, Warnock D, Laghi F, Goldstein SL, Prielipp R, Parikh CR, Pannu N, Lobo SM, Shah S, D'Intini V, Kellum JA. Evaluation and initial management of acute kidney injury. Clin J Am Soc Nephrol 2008;3(4):962-7.

41. Chertow GM, Burdick E, Honour M, Bonventre JV, Bates DW. Acute kidney injury, mortality, length of stay, and costs in hospitalized patients. J Am Soc Nephrol 2005;16(11):3365-70.

42. Bagshaw SM, Bellomo R. Urine abnormalities in acute kidney injury and sepsis. Contrib Nephrol 2010;165:274-83.

43. Bagshaw SM, Langenberg C, Bellomo R. Urinary biochemistry and microscopy in septic acute renal failure: a systematic review. Am J Kidney Dis 2006;48(5):695-705.

44. Carvounis CP, Nisar S, Guro-Razuman S. Significance of the fractional excretion of urea in the differential diagnosis of acute renal failure. Kidney Int 2002;62(6):2223-9.

45. Perazella MA, Coca SG, Kanbay M, Brewster UC, Parikh CR. Diagnostic value of urine microscopy for differential diagnosis of acute kidney 
injury in hospitalized patients. Clin J Am Soc Nephrol 2008;3(6):16159.

46. Bagshaw SM, Langenberg C, Haase M, Wan L, May CN, Bellomo R. Urinary biomarkers in septic acute kidney injury. Intensive Care Med 2007;33(7):1285-96.

47. Kokot M, Biolik G, Ziaja D, Fojt T, Cisak K, Antoniak K, KowalewskaTwardela T, Pawlicki K, Ziaja K, Duława J. Acute kidney injury after abdominal aortic aneurysm surgery: detailed assessment of early effects using novel markers. Pol Arch Med Wewn 2012;122(7-8):353 60.

48. Nejat M, Pickering JW, Devarajan P, Bonventre JV, Edelstein CL, Walker RJ, Endre ZH. Some biomarkers of acute kidney injury are increased in pre-renal acute injury. Kidney Int 2012;81(12):1254-62.

49. Cho E, Yang HN, Jo SK, Cho WY, Kim HK. The role of urinary liver-type fatty acid-binding protein in critically ill patients. J Korean Med Sc 2013;28(1):100-5.

50. Dent CL, Ma Q, Dastrala S, Bennett M, Mitsnefes MM, Barasch J, Devarajan P. Plasma neutrophil gelatinase-associated lipocalin predicts acute kidney injury, morbidity and mortality after pediatric cardiac surgery: a prospective uncontrolled cohort study. Crit Care 2007;11(6):R127.

51. Han WK, Waikar SS, Johnson A, Betensky RA, Dent CL, Devarajan $\mathrm{P}$, Bonventre JV. Urinary biomarkers in the early diagnosis of acute kidney injury. Kidney Int 2008;73(7):863-9.

52. Belcher JM, Edelstein CL, Parikh CR.Clinical applications of biomarkers for acute kidney injury. Am J Kidney Dis 2011;57(6):930-40.

53. Devarajan P. Emerging biomarkers of acute kidney injury. Contrib Nephrol 2007;156:203-12.

54. Parikh CR, Edelstein CL, Devarajan P, Cantley L. Biomarkers of acute kidney injury: early diagnosis, pathogenesis, and recovery. J Investig Med 2007;55(7):333-40.

55. Kashani K, Al-Khafaji A, Ardiles T, Artigas A, Bagshaw SM, Bell M Bihorac A, Birkhahn R, Cely CM, Chawla LS, Davison DL, Feldkamp T, Forni LG, Gong MN, Gunnerson KJ, Haase M, Hackett J, Honore PM, Hoste EA, Joannes-Boyau O, Joannidis M, Kim P, Koyner JL, Laskowitz DT, Lissauer ME, Marx G, McCullough PA, Mullaney S, Ostermann M, Rimmelé T, Shapiro NI, Shaw AD, Shi J, Sprague AM, Vincent JL, Vinsonneau C, Wagner L, Walker MG, Wilkerson RG, Zacharowski K, Kellum JA. Discovery and validation of cell cycle arrest biomarkers in human acute kidney injury. Crit Care 2013;17(1):R25.

56. Hong DY, Lee JH, Park SO, Je Baek K, Lee KR. Plasma Neutrophi Gelatinase-associated Lipocalin as Early Biomarker for Acute Kidney Injury in Burn Patients. J Burn Care Res 2013 Mar 18. [Epub ahead of print]

57. Martino FK, Filippi I, Giavarina D, Kaushik M, Rodighiero MP, Crepaldi C, Teixeira C, Nadal AF, Rosner MH, Ronco C. Neutrophil gelatinaseassociated lipocalin in the early diagnosis of peritonitis: the case of neutrophil gelatinase-associated lipocalin. Contrib Nephro 2012;178:258-63.

58. Koyner JL, Garg AX, Shlipak MG, Patel UD, Sint K, Hong K, Devarajan $\mathrm{P}$, Edelstein CL, Zappitelli M, Thiessen-Philbrook H, Parikh CR Translational Research Investigating Biomarker Endpoints in AK (TRIBE AKI) Consortium. Urinary Cystatin C and Acute Kidney Injury After Cardiac Surgery. Am J Kidney Dis 2013 Jan 15 [Epub ahead of print] doi:10.1053/j.ajkd.2012.12.006

59. Zhang Z, Ni H, Lu B, Jin N. Elevated serum Cystatin $\mathrm{C}$ at continuous renal replacement therapy initiation predicts lack of renal recovery. Clin Nephrol 2013 Jan 15. [Epub ahead of print]

60. Coppolino G, Presta P, Saturno L, Fuiano G. Acute kidney injury in patients undergoing cardiac surgery. J Nephrol 2013;26(1):32-40.

61. Lee DW, Faubel S, Edelstein CL. Cytokines in acute kidney injury (AKI). Clin Nephrol 2011;76(3):165-73.

62. Zhu HH, Jiang LL. Serum inter-cellular adhesion molecule 1 is an early marker of diagnosis and prediction of severe acute pancreatitis. World J Gastroenterol 2012;18(20):2554-60.

63. Jiang K, Huang W, Yang XN, Xia Q. Present and future of prophylactic antibiotics for severe acute pancreatitis. World J Gastroentero 2012;18(3):279-84

64. Nicholson LJ. Acute pancreatitis: should we use antibiotics? Curr Gastroenterol Rep 2011;13(4):336-43.

65. Anand N, Park JH, Wu BU. Modern management of acute pancreatitis. Gastroenterol Clin North Am 2012;41(1):1-8.

66. Takeda K, Takada T, Kawarada Y, Hirata K, Mayumi T, Yoshida M Sekimoto M, Hirota M, Kimura Y, Isaji S, Koizumi M, Otsuki M, Matsuno S; JPN."JPN Guidelines for the management of acute pan- creatitis: medical management of acute pancreatitis. J Hepatobiliary Pancreat Surg 2006;13(1):42-7.

67. Doctor N, Agarwal P, Gandhi V. Management of severe acute pancreatitis. Indian J Surg 2012;74(1):40-6.

68. Zhang XP, Zhang L, Wang Y, Cheng QH, Wang JM, Cai W, Shen HP, Cai J. Study of the protective effects of dexamethasone on multiple organ injury in rats with severe acute pancreatitis. JOP 2007;8(4):40012.

69. Le Campion ER, Jukemura J, Coelho AM, Patzina R, Carneiro D'Albuquerque LA. Effects of intravenous administration of pentoxifylline in pancreatic ischaemia-reperfusion injury. HPB (Oxford) 2012 Dec 17. [Epub ahead of print] doi: 10.1111/hpb.12013.

70. Du XG, Chen XM, Gan H, Li ZR, Wen YJ, Wang XC. Continuous blood purification ameliorates RhoA-mediated endothelial permeability in severe acute pancreatitis patients with lung injury. Int J Artif Organs 2011;34(4):348-56.

71. Wang S, Xu L, Feng X, Li S, Feng Q, Liu C, Zhang X, Zhao Q. Is Continuous Venovenous Hemofiltration Effective Against Severe Acute Pancreatitis? Artif Organs 2013 Mar 5. [Epub ahead of print] doi: 10.1111/aor.12051.

72. Gong D, Zhang P, Ji D, Chen Z, Li W, Li J, Li L, Liu Z. Improvement of immune dysfunction in patients with severe acute pancreatitis by high-volume hemofiltration: a preliminary report. Int J Artif Organs 2010;33(1):22-9.

73. Chu LP, Zhou JJ, Yu YF, Huang Y, Dong WX. Clinical effects of pulse high-volume hemofiltration on severe acute pancreatitis complicated with multiple organ dysfunction syndrome. Ther Apher Dial 2013;17(1):78-83.

74. Zhu Y, Yuan J, Zhang P, Hu X, He Q, Han F, Chen J. Adjunctive continuous high-volume hemofiltration in patients with acute severe pancreatitis: a prospective nonrandomized study. Pancreas 2011;40(1)109-13.

75. Yang C, Guanghua F, Wei Z, Zhong J, Penghui J, Xin F, Xiping Z. Combination of hemofiltration and peritoneal dialysis in the treatment of severe acute pancreatitis. Pancreas 2010;39(1):16-9.

76. Yu C, Liu ZH, Chen ZH, Gong DH, Ji DX, Li LS. Improvement of monocyte function and immune homeostasis by high volume continuous venovenous hemofiltration in patients with severe acute pancreatitis. Int J Artif Organs 2008;31(10):882-90.

77. Pupelis G, Plaudis H, Grigane A, Zeiza K, Purmalis G. Continuous veno-venous haemofiltration in the treatment of severe acute pancreatitis: 6-year experience. HPB (Oxford) 2007;9(4):295-301.

78. Chen ZH, Liu ZH, Yu C, Ji DX, Li LS. Endothelial dysfunction in patients with severe acute pancreatitis: improved by continuous blood purification therapy. Int J Artif Organs 2007;30(5):393-400.

79. Jiang HL, Xue WJ, Li DQ, Yin AP, Xin X, Li CM, Gao JL. Influence of continuous veno-venous hemofiltration on the course of acute pancreatitis. World J Gastroenterol 2005;11(31):4815-21.

80. Oda S, Hirasawa H, Shiga H, Matsuda K, Nakamura M, Watanabe $\mathrm{E}$, Moriguchi T. Management of intra-abdominal hypertension in patients with severe acute pancreatitis with continuous hemodiafiltration using a polymethyl methacrylate membrane hemofilter. Ther Apher Dial 2005;9(4):355-61.

81. Wang H, Li WQ, Zhou W, Li N, Li JS. Clinical effects of continuous high volume hemofiltration on severe acute pancreatitis complicated with multiple organ dysfunction syndrome. World J Gastroenterol 2003;9(9):2096-9.

82. Xie H, Ji D, Gong D, Liu Y, Xu B, Zhou H, Liu Z, Li L, Li W, Quan Z, Li J. Continuous veno-venous hemofiltration in treatment of acute necrotizing pancreatitis. Chin Med J (Engl). 2003;116(4):549-53.

83. Leppäniemi A, Johansson K, De Waele JJ. Abdominal compartment syndrome and acute pancreatitis. Acta Clin Belg Supp. 2007;(1):1315.

84. Malbrain $M L$, Chiumello D, Pelosi $P$, Wilmer A, Brienza N, Malcangi V, Bihari D, Innes $R$, Cohen J, Singer $P$, Japiassu A, Kurtop E, De Keulenaer BL, Daelemans R, Del Turco M, Cosimini P, Ranieri M, Jacquet L, Laterre PF, Gattinoni LPrevalence of intra-abdominal hypertension in critically ill patients: a multicentre epidemiological study. Intensive Care Med 2004;30(5):822-9.

85. Malbrain ML, Deeren DH. Effect of bladder volume on measured intravesical pressure: a prospective cohort study. Crit Care 2006;10(4):R98

86. Malbrain $\mathrm{ML}$, Jones $\mathrm{F}$. Intra-Abdominal pressure measurement techniques. In: Ivatury RR, Cheatham ML, Malbrain ML, Sugrue M. 
Abdominal compartment syndrome. Georgetown USA: Landes Bioscience 2006; p. 20-68.

87. Desie N, Willems A, De Laet I, Dits H, Van Regenmortel N Schoonheydt K, Van De Vyvere M, Malbrain ML. Intra-abdominal pressure measurement using the Foley Manometer does not increase the risk for urinary tract infection in critically ill patients. Ann Intensive Care 2012;2 Suppl 1:S10.

88. McBeth PB, Zengerink I, Zygun D, Ranson K, Anderson I, Lall RN, Kirkpatrick AW. Comparison of intermittent and continuous intraabdominal pressure monitoring using an in vitro model. Int J Clin Pract 2008;62(3):400-5.

89. De Waele JJ, Hoste E, Blot SI, Decruyenaere J, Colardyn F. Intraabdominal hypertension in patients with severe acute pancreatitis. Crit Care 2005;9(4):R452-7.

90. Plaudis H, Rudzats A, Melberga L, Kazaka I, Suba O, Pupelis G. Abdominal negative-pressure therapy: a new method in countering abdominal compartment and peritonitis - prospective study and critical review of literature. Ann Intensive Care 2012;2 Suppl 1:S23.

91. Haldipur N, Cooper B, Sanyal S. Managing the open abdomen. J R Army Med Corps 2006;152(3):143-7.

92. Björck M, Bruhin A, Cheatham M, Hinck D, Kaplan M, Manca G, Wild T, Windsor A. Classification--important step to improve management of patients with an open abdomen. World J Surg 2009;33(6):1154-7.

93. Boele van Hensbroek P, Wind J, Dijkgraaf MG, Busch OR, Goslings JC. Temporary closure of the open abdomen: a systematic review on delayed primary fascial closure in patients with an open abdomen. World J Surg 2009;33(2):199-207.

94. Balogh Z, McKinley BA, Cocanour CS, Kozar RA, Valdivia A, Sailors RM, Moore FA. Supranormal trauma resuscitation causes more cases of abdominal compartment syndrome. Arch Surg 2003;138(6):637-42.

95. Peng ZY, Critchley LA, Joynt GM, Gruber PC, Jenkins CR, Ho AM Effects of norepinephrine during intra-abdominal hypertension on renal blood flow in bacteremic dogs. Crit Care Med 2008;36(3):83441.

96. Bellomo R, Kellum JA, Wisniewski SR, Pinsky MR. Bellomo R, Kellum $J A$, Wisniewski SR, Pinsky MR. Effects of norepinephrine on the renal vasculature in normal and endotoxemic dogs. Am J Respir Crit Care Med 1999;159(4 Pt 1):1186-92.
97. Albert M, Losser MR, Hayon D, Faivre V, Payen D. Systemic and renal macro- and microcirculatory responses to arginine vasopressin in endotoxic rabbits. Crit Care Med 2004;32(9):1891-8.

98. Desjars P, Pinaud M, Potel G, Tasseau F, Touze MD. A reappraisal of norepinephrine therapy in human septic shock. Crit Care Med 1987;15(2):134-7.

99. Hesselvik JF, Brodin B. Low dose norepinephrine in patients with septic shock and oliguria: effects on afterload, urine flow, and oxygen transport. Crit Care Med 1989;17(2):179-80.

100. Hollenberg SM. Vasopressor support in septic shock. Chest 2007;132(5):1678-87.

101. Yuengsrigul A, Chin TW, Nussbaum E. Immunosuppressive and cytotoxic effects of furosemide on human peripheral blood mononuclear cells. Ann Allergy Asthma Immunol 1999;83(6 Pt 1):559-66.

102. Bagshaw SM, Bellomo R, Kellum JA. Oliguria, volume overload, and loop diuretics. Crit Care Med 2008;36(4 Suppl):S172-8.

103. Glassford NJ, Bellomo R. Acute kidney injury: Fluid therapy in acute kidney injury: the FACTTs. Nat Rev Nephrol 2011;7(6):305-6.

104. Zhang XP, Tian H, Lai YH, Chen L, Zhang L, Cheng QH, Yan W, Li Y, $\mathrm{Li}$ QY, He Q, Wang F. Protective effects and mechanisms of Baicalin and octreotide on renal injury of rats with severe acute pancreatitis. World J Gastroenterol 2007;13(38): 5079-89.

105. Oudemans-van Straaten HM, Kellum JA, Bellomo R. Clinical review: anticoagulation for continuous renal replacement therapy-heparin or citrate? Crit Care 2011;15(1):202.

106. Uehlinger $D E$, Jakob $S M$, Ferrari $P$, Eichelberger M, Huynh-Do $U$, Marti HP, Mohaupt MG, Vogt B, Rothen HU, Regli B, Takala J, Frey FJ. Comparison of continuous and intermittent renal replacement therapy for acute renal failure. Nephrol Dial Transplant 2005;20(8):1630-7.

107. Palevsky PM, Zhang JH, O'Connor TZ, Chertow GM, Crowley ST, Choudhury D, Finkel K, Kellum JA, Paganini E, Schein RM, Smith MW, Swanson KM, Thompson BT, Vijayan A, Watnick S, Star RA, Peduzzi P. VA/NIH Acute Renal Failure Trial Network. Intensity of renal support in critically ill patients with acute kidney injury. $\mathrm{N}$ Engl J Med 2008;359(1):7-20.

108. Uchino S. What is 'BEST' RRT practice? Contrib Nephrol 2010;165:244-50 